Research Article

\title{
A Quasi-Experimental Study to Evaluate the Effectiveness of Self-Instructional Module (SIM) regarding Non-Communicable Diseases (NCD) among Nursing Officers in Terms of Knowledge
}

\author{
Sunita Dixit', Urmila D Bhardwaj', Asha T Aniyan $^{3}$
}

${ }^{1}$ M.Sc. Nursing (Obstetrics and Gynaecological Nursing) Student, ${ }^{2}$ Principal, ${ }^{3}$ Tutor, Rufaida College of Nursing, Jamia Hamdard, New Delhi.

DOI: https://doi.org/10.24321/2455.9318.201926

\section{I $\quad \mathbf{N} \quad \mathbf{F} \quad \mathbf{O}$}

\section{Corresponding Author:}

Sunita Dixit, Rufaida College of Nursing, Jamia

Hamdard, New Delhi.

E-mail Id:

sunitadixit2307@gmail.com

Orcid Id:

https://orcid.org/0000-0001-7456-5985

How to cite this article:

Dixit S, Bhardwaj UD, Aniyan AT. A QuasiExperimental Study to Evaluate the Effectiveness of Self-Instructional Module (SIM) regarding NonCommunicable Diseases (NCD) among Nursing Officers in Terms of Knowledge. Int J Nurs Midwif Res 2019; 6(4): 8-12.

Date of Submission: 2019-06-14

Date of Acceptance: 2020-02-26

\section{$\begin{array}{lllllllllll}\mathbf{A} & \mathbf{B} & \mathbf{S} & \mathbf{T} & \mathbf{R} & \mathbf{A} & \mathbf{C} & \mathbf{T}\end{array}$}

Introduction: As a part of the Government of India's commitment to ensure availability of quality services through public health institutions, National Programme for Prevention and Control of Cancer, Diabetes, Cardiovascular Disease and Stroke (NPCDCs) was launched in 2010 in 100 districts across 21 states of India in order to control and prevent the major non-communicable diseases. It provided a platform for augmentation of the knowledge of health personnel involved in the health services across public health institutions.

Objective: The present study was conducted to evaluate the effectiveness of Self Instructional Module (SIM) regarding Non-Communicable Diseases (NCD).

Materials and Methods: A quasi-experimental research design, experimental and control group pre-test and post-test design was used to synthesize research findings related to effectiveness of SIM among 80 Nursing Officers from Jag Pravesh Chandra Hospital \& Swami Dayanad Hospital, Delhi through a Structured Knowledge Questionnaire. Data were analyzed using descriptive and inferential statistics.

Result: Findings revealed that 41 (55\%) had average knowledge, 25 (31.25\%) had good knowledge and 11 (13.75\%) had poor knowledge regarding non-communicable diseases in both experimental and control group in pre-test. z-value in experimental group was 10.17, which is statistically significant; whereas, z-value in control group was 0.48 at 0.05 level of significance.

Conclusion: The present study revealed that most of Nursing Officers had average to good knowledge, but due to over burden, patients and lack of time to study, they were not able to retain their knowledge. They require regular rebooting of their knowledge. It was observed that Self Instructional Module on NCD was effective teaching material for Nursing Officers working in Government Hospitals.

Keywords: NPCDCS, SIM, Nursing Officers, NCD 


\section{Introduction}

India is a vast, heterogeneous country with an approximate population of 1.3 billion people, ${ }^{1}$ a complex socio-economic milieu, and immense diversity in culture, diets and customs. Behavioral and social science insight are the burden of noncommunicable diseases in the India. ${ }^{2}$ Primarily cardiovascular disease, diabetes, hypertension, stroke, cancers, and obesity were prevalent among the higher income groups. But now the burden of non-communicable diseases shifted to the developing world. ${ }^{3}$ NCDs are strongly influenced by social and behavioral factors. ${ }^{2}$ Non-Communicable Disease (NCDs) is a medical condition or disease that is not caused by infectious agents (non-infectious or non-transmissible). ${ }^{4}$

The increasing bad impact of behavioral practices on mortality highlights the importance of a lifestyle changing approach to lowering the risk of developing NCDs among the young people. ${ }^{5}$ At a time of rising concern about the current and future burden of NCDs in the developing world, there are a number of opportunities involving data, research, programmatic and policy initiatives centered on the role of nursing officers that should be pursued. ${ }^{6}$

Nursing officers are increasingly being recognized as a crucial part of the health workforce in India and worldwide. They have provided health care to communities for many decades and have assumed a variety of roles, including community empowerment, provision of services and linking communities with health facilities. ${ }^{7}$ Roles of nursing officers are better understood in the different areas. The present study was conducted with the following objectives.

- To develop a self-instructional module on NonCommunicable Diseases for Nursing Officers

- To evaluate the effectiveness of the module in terms of knowledge on Non-Communicable Diseases

\section{Materials and Methods}

A quantitative research approach was used in this study to explore the effectiveness of SIM on NCD among nursing officers of Swami Dayanand Hospital ${ }^{8}$ and Jag Pravesh Chandra Hospitals ( $1^{\text {st }}$ oct to $20^{\text {th }}$ oct 2018 ) and Jag Pravesh Chandra Hospital (10 ${ }^{\text {th }}$ oct to $30^{\text {th }}$ oct 2018 ) in Delhi, India. Quasi experimental non-equivalent pre-test post-test control group design was used. A convenient sampling technique was used to select 80 participants who were allocated into experimental and control $(n 1+n 2=80)$ groups. Nursing officers working in causality, OPD and O.T were exclude from the study. The research instrument was structured knowledge questionnaire on NCD, which was developed on the basis of literature review and expert consultation.

The material is sequentially arranged in units and allowed self-paced to participants for the independent learning. A formal permission was obtained from the authorities of both hospitals, to conduct this study. Participants were given full explanation regarding the objective of the study and written consent taken measure of confidentiality maintained. The structured knowledge questionnaire has 2 parts including 6 sections. In the first part, socio demographic information of nursing officers was included whereas the second part consisted of 6 sections regarding general information on NCD, hypertension, diabetes mellitus, cancer, stroke and obesity. There were $40 \mathrm{MCQ}$ items with each question comprised of three distracters and one correct option. A score of 1 was assigned to each correct option and zero was assigned to incorrect option selected by the participants. The overall score was used to judge participants knowledge level as good knowledge (31-40), average (20-30) and below 20 is poor knowledge.

Pre-test conducted on the same day, followed by posttest at the gap of 7 days by using same tool in both the groups. Data were analyzed using SPSS. Descriptive analysis such as percentage, frequency, mean, SD, as well as z value was calculated.

\section{Result}

\section{Finding Related to Demographic Data of Nursing Officers}

Data presented in Figure 1, depicting the demographic profile/ characteristics pertaining to age, work experience, educational qualification, BMI and health status of nursing officers in both experimental and control group. Majority (57.5\%) of participants who were in $31-40$ years of age. About $37.5 \%$ of the participants had $11-15$ years of working experience in Government Hospitals and 60\% of the participants possess Diploma in Nursing. The BMI of $43.7 \%$ of the participants were found in overweight category. Only $5 \%$ of the subjects were likely to developed any non-communicable diseases.

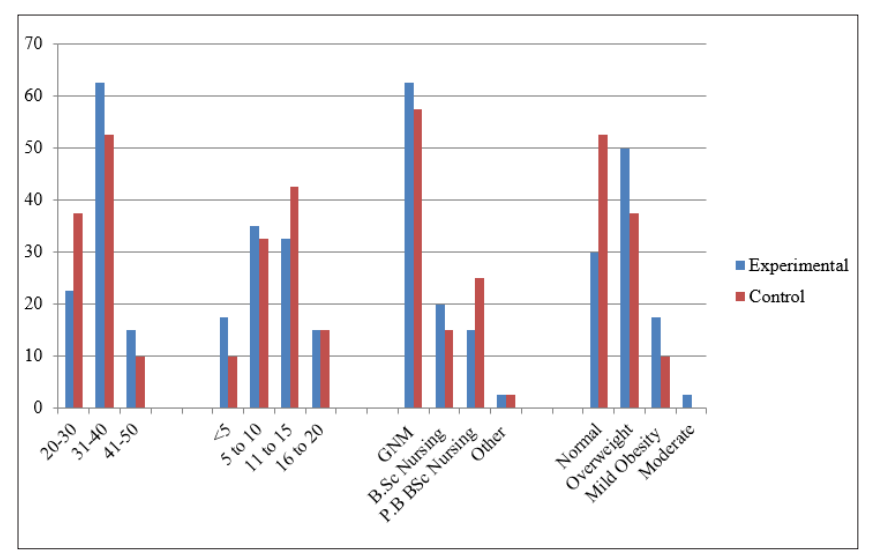

Figure I.Simple Bar diagram depicting percentage frequency and demographic profile of experimental and control group 
Findings related to evaluation of effectiveness of SIM in terms of knowledge of Nursing Officers

Table 1 , depicts that, only $22.35 \%$ of participants in experimental group had good knowledge, whereas $57.5 \%$ had average knowledge and $20 \%$ had poor knowledge. On the other hand, in control group $40 \%$ of participants had good knowledge whereas $52.5 \%$ had average knowledge. Only $7.5 \%$ had poor knowledge.

Data presented in Table 2, depicting that the $z$ value is $10.17^{*}$ in Experimental group, which is greater than the table value. $z$ i.e.1.64 at 0.05 level of significance, thus we reject null hypothesis and accept the research hypothesis, which is there will be a significant difference in the mean pre-test \& post-test knowledge scores of Nursing Officers regarding Non Communicable Diseases after administration of SIM as evident from the structured knowledge questionnaire at 0.05 level of significance. This indicates that the significance was due to the SIM and not by chance.

Data presented in Table 2, Shows that the calculated z-value compression of in Experimental Group (n1) was 10.17* than the control group (n2) z-value compression 0.48 , which was significant at 0.05 level.

Data presented inTable3, Shows that the calculated z-value compression of in Experimental Group (n1) Control group $\left(n^{2}\right)$ was $|z|=7.425>Z c=1.96$, it is then concluded the null hypo-thesis is rejected which is statistically significant. ( $p$ -value=0). Hence the SIM is effective.

\section{Discussion}

The present study findings revealed that there was a significant increase in the post- test knowledge score after administration of Self-Instructional Module in Experimental group, z-value is $10.17^{*}$.

The present study aimed to evaluate the knowledge of nursing officer's regarding non communicable diseases was found similar to a study conducted by Nwozichi CU et al to assess $^{9}$ the effectiveness of Self-Instructional Module (SIM) in enhancing knowledge of Ebola virus diseases among 60 Nigerian students. The results were the mean pre-test score was 16.03 with an SD of 22.951, while the mean posttest knowledge score was 28.22 with SD of 3.273. The calculated $t$-value was $21.432(P<0.001)$.

The study revealed findings was similar to the findings of research study conducted by Jose $S$ and Solomon SG ${ }^{10}$ to evaluate the effectiveness of self-instructional module on knowledge regarding learning disabilities of primary school children among 60 primary school teachers of selected schools in Indore by using purposive sampling method. Pre-test and post-test knowledge score in experimental group in pre-test mean score and standard deviation was $16.6 \pm 3.03$ respectively and post-test mean score and standard deviation was $33.3 \pm 2.01$. The $p$-value was 22.61 and $P=0.001$, in these primary school teachers have improved their knowledge from 16.62 to 33.3 on learning disabilities. The comparison of pre-test and post-test knowledge score was in control group in this pre-test mean score and standard deviation was $17.23 \pm 2.06$ and post-test mean score and standard deviation was $19.13 \pm 2.11$ and $\mathrm{t}=1.93, \mathrm{P}=0.06$ in this the primary school teachers lightly improved their knowledge.

Table I.Categories of pre-test knowledge scores, possible range, obtained range, frequency and percentage obtained

$(\mathrm{n} 1+\mathrm{n} 2=80)$

\begin{tabular}{|c|c|c|c|c|c|c|}
\hline \multirow[b]{2}{*}{$\begin{array}{l}\text { Categories of pre-test } \\
\text { knowledge scores }\end{array}$} & \multirow{2}{*}{$\begin{array}{c}\text { Possible range } \\
\text { of pretest } \\
\text { knowledge } \\
\text { scores }\end{array}$} & \multirow{2}{*}{$\begin{array}{c}\text { Obtained range } \\
\text { of pre-test } \\
\text { knowledge } \\
\text { scores }\end{array}$} & \multicolumn{2}{|c|}{ Experimental group (n1) } & \multicolumn{2}{|c|}{ Control group (n2) } \\
\hline & & & $\begin{array}{l}\text { Frequency } \\
\text { (f) }\end{array}$ & $\begin{array}{c}\text { Percentage } \\
\text { (\%) }\end{array}$ & $\begin{array}{c}\text { Frequency } \\
\text { (f) }\end{array}$ & $\begin{array}{c}\text { Percentage } \\
(\%)\end{array}$ \\
\hline Poor Knowledge (Below 20) & \multirow{3}{*}{$0-40$} & \multirow{3}{*}{$16-39$} & 8 & 20 & 3 & 7.5 \\
\hline Average Knowledge (20-30) & & & 23 & 57.5 & 21 & 52.5 \\
\hline Good Knowledge (31-40) & & & 9 & 22.35 & 16 & 40 \\
\hline
\end{tabular}

Table 2.Mean, Standard Deviation Obtained from data and Z Value for Experimental and Control Group

$(\mathrm{n} 1+\mathrm{n} 2=80)$

\begin{tabular}{|c|c|c|c|c|}
\hline Group & Knowledge Score & Mean Knowledge Score & SD & z-value \\
\hline \multirow{2}{*}{ Experimental Group (n1) } & 26.27 & 5.36 & \multirow{2}{*}{$10.17^{*}$} \\
\cline { 2 - 5 } & Pre-test Knowledge Score & 36.05 & 3.12 & 4.84 \\
\hline \multirow{2}{*}{ Control group (n2) } & Pre-test Knowledge Scores & 28.27 & \multirow{2}{*}{0.48} \\
\cline { 2 - 5 } & Post-test Knowledge Score & 28.82 & 5.31 \\
\hline
\end{tabular}

$z(38)=1.64 p<0.05$ significant at 0.05 level of significance. 
Table 3. Mean $\pm S D$ and $Z$ value for posttest in experimental and control group

$(\mathrm{n} I+\mathrm{n} 2=80)$

\begin{tabular}{|c|c|c|c|}
\hline Group & Mean士 SD Post-test Scores & Mean difference & Z-Value \\
\hline Experimental Group (n1) & $36.05 \pm 3.12$ & 7.23 & \multirow{2}{*}{7.425} \\
\hline Control Group (n2) & $28.82 \pm 5.31$ & & \\
\hline
\end{tabular}

The study revealed finding were similar to the finding of research study evaluated the effectiveness of a selfinstructional module developed by the Mary-Charles Santo Pietro for nursing student for dealing human sexuality counseling of male myocardial patients in United states. Total 161 nursing student were selected by using convenient sampling techniques and pre-post testing of subjects on a knowledge inventory and behavioral intensions/comfort inventory. Following administration of module, experimental subjects score indicated significant increase in knowledge of sexuality counseling of MI patients ( $p$ less than 0.001) and comfort in dealing with patients' sexuality cancers ( $p$ less than 0.001).

\section{Conclusion}

The study revealed that presently most of the nursing officers working in government Hospitals were GNM and due to constrain of time they are unable to study regularly. Self-instructional module on Non-Communicable Diseases was effective as a way of teaching in present study and helped them in adopting to health-related information in clinical practice.

\section{Conflict of Interest: None}

\section{References}

1. Verma R, Khanna P, Mehta B. National programme on prevention and control of diabetes in India: Need to focus. Australasian Medical Journal 2012; 5(6): 310315. [PubMed/ Google Scholar].

2. National Programme for Prevention and Control of Cancer, Diabetes, Cardiovascular Diseases and Stroke (NPCDCS). Available from: https://dghs.gov.in/content/1363_3_ NationalProgrammePreventionControl.aspx. Directorate Journal of Health Services. Government of India.

3. Nethan S, Sinha D, Mehrotra R. Non communicable disease risk factors and their trends in India. Asia Pacific Journal of Cancer Prevention 2017; 18(7): 2005-2010. [PubMed/ Google Scholar].

4. Non-communicable disease. Available from: https:// en.wikipedia.org/wiki/Non-communicable_disease.

5. Patton GC, Sawyer SM, Santelli JS, Ross DA, Afifi R, Allen NB et al. Our future: a Lancet commission on adolescent health and wellbeing. Lancet 2016; 387(10036): 24232478. Available from: https://www.thelancet.com/ journals/lancet/article/PIIS0140-6736(16)00579-1/ fulltext [PubMed/ Google Scholar].

6. Bachani D, Srivastava R. Burden of NCDs, policies and programme for prevention and control of NCDs in India. Indian Journal of Community Medicine 2011; 36(5): 7-12. Available from: http://www.ijcm.org.in/article. asp? issn=0970-0218; year=2011; volume=36;issue=5;s page $=7$; epage $=12$; aulast=Srivastava [Google Scholar].

7. Tsolekile LP, Puoane T, Schneider H, Levitt NS, Steyn K. The roles of community health workers in management of non-communicable diseases in an urban township. Journal of Primary Health Care and Family Medicine 2014; 6(1): a693. [PubMed/ Google Scholar].

8. Folayan M, Peterson K, Haire B, Brown B, Audu K, Makanjuola O. Debating ethics in HIV research: gaps between policy and practice in Nigeria. Developing World Bioethics 2014; 15(3): 214-225. Available from: https://onlinelibrary.wiley.com/doi/abs/10.1111/ dewb.12064 [PubMed/ Google Scholar].

9. Theguardian.com/world/2017/may/24/India-is-worldmost-population-with-132bn-people-academic-c/aims.

10. Non-Communicable Diseases | (Internet). Ghwatch. org. Available from: https://ghwatch.org/who-watch/ topics/ncd 2018.

11. Global status report on non-communicable diseases (Internet). World Health Organization. Available from: http://www.who,int/nmh/publications/ncd report2010/en http://www.who.int/nmh/publications/ ncd_report2010/en.

12. Bachani D, Srivastava R. Burden of NCDs, Policies and Programme for Prevention and Control of NCDs in India. Indian Journal of Community Medicine 2011; 36(5): 7-12. Available from: http://www.ijcm.org.in/article. asp? issn=0970-0218; year=2011; volume $=36$;issue=5; page $=7$; epage $=12$; aulast=Srivastava [Google Scholar] .

13. Gamge AU, JayawardanaPL. Knowledge on noncommunicable diseases and practices related to healthy lifestyle amomng adolescents, in state schools of selected educational division in Sri lanka (Internet) Health BMC series-open inclusive and trusted 201718:64. Available from: https//doi/10.1186/s12880017-4622.

14. Negi PC, Chauhan R, Rana V, Vidyasagar, Lal K. Epidemiological study of non-communicable diseases (NCD) risk factors in tribal district of Kinnaur, HP: A crosssectional study. Indian Heart Journal 2016; 68(5): 655662. Available from: https://www.sciencedirect.com/ 
science/article/pii/S0019483216001036?via\%3Dihub [PubMed/ Google Scholar].

15. Jaskiewicz W, Tulenko K. Increasing communinity health worker productivity and effectiveness: a review of the influence of the work environment. Human Resources for Health 2012; 10: 38. Available from: https://human-resources-health.biomedcentral.com/ articles/10.1186/1478-4491-10-38 [Google Scholar].

16. Burn and Groove, understanding Nursing Research and Building on evidenced based practice. $4^{\text {th }}$ ed. India. Elsevier; 2008.

17. Nwozichi C, Ojewole F, Farotimi A, Ojediran T. . Journal of Education and Health Promotion 2016; 5(1): 4. Available from: http://www.jehp.net/article.asp?issn=22779531; ;ear $=2016$; volume $=5$; issue $=1$; ;page $=4$; epage $=$ 4;aulast=Nwozichi [Google Scholar].

18. Jose S, Solomon SG. A study to evaluate the effectiveness of self instructional module on knowledge regarding learning disabilities of primary school children among primary school teachers of selected school at Indore, M.P.ISSN:0975-833X;IMPACTFACTOR:7.749.

19. Santopietro MC. Effectiveness of a self-instructional Module in Human Sexuality Counselling of MI patients among nursing students. Nursing Reasrch 1980; 29(1): 14-19. Available from: https://europepmc.org/article/ med/6898027 [Google Scholar]. 